\title{
TRAYECTORIAS DEL RELATIVISMO MODERNO Y SU ONTOLOGÍA POLÍTICA: ENTRE LA POSVERDAD Y LA HIPERVERDAD
}

\author{
Carlos A. Manrigue* \\ doi: 10.11144/Javeriana.uph36-72.trmo
}

\section{RESUMEN}

Este artículo problematiza el difundido diagnóstico sobre la relación entre política y verdad, o política y mentira, que se moviliza con el vocablo posverdad. Primero, se cuestiona la presunta novedad histórica que este pretende identificar, recordando cómo la filosofía política en Occidente ha estado atravesada por una ansiedad frente a la fuerza amenazante de un discurso huérfano y errante que circula sin conciencia y sin referente. Segundo, se indican las limitaciones del reproche en relación con la retirada de la razón y la veracidad de la política, y su falla en atender a cómo, desplazándonos del campo de la política electoral al de la técnica gubernamental, opera hoy una producción de la verdad de lo social en un discurso tecnocientífico hegemónico. Tercero, se muestra que hay una coherencia estructural entre la técnica gubernamental de la hiperverdad y el inescrupoloso interés estratégico en la realpolitik de la política electoral, coherencia anclada en las premisas ontológicas y epistémicas de la concepción moderna de lo político. Finalmente, se destaca la potencia crítica que ante este panorama nos ofrece aún el legado del posestructuralismo.

Palabras clave: posverdad; ontología política; gubernamentalidad; posestructuralismo

Universidad de los Andes, Bogotá, Colombia.

Correo electrónico: ca.manrique966@uniandes.edu.co

Para citar este artículo: Manrique, Carlos A. (2019). Trayectorias del relativismo moderno y su ontología política: entre la posverdad y la hiperverdad. Universitas Philosophica, 36(72), 151-172. ISSN 0120-5323, ISSN en línea 2346-2426. doi: 10.11144/Javeriana.uph36-72.trmo 


\title{
TRAJECTORIES OF MODERN RELATIVISM AND ITS POLITICAL ONTOLOGY: IN BETWEEN POST-TRUTH AND HYPER-TRUTH
}

\begin{abstract}
This article problematizes the extended diagnosis regarding the relation between truth and politics, or politics and lies, mobilized by the term post-truth. First, it puts into question the presumed historical novelty that the term signals to, reminding us how Western political philosophy has always been marked by the anxiety towards the threathening force of an orphan and erratic discourse with no consciousness and no referent. Second, it indicates the limitations of the reproach against the presumed withdrawal of rationality and veracity from politics, insofar as it fails to take into account the extent to which there is operative nowadays, in a hegemonic tecno-scientific discourse, a production of a certain truth of the social. In order to attend to this other angle of the relation between truth and politics one needs to displace the view from the field of electoral politics, to the field of techniques of government. Third, the article argues that there is a structural coherence between the hyper-truth in which these government techniques operate, and the inescrupulous strategic interest in the realpolitik of electoral politics, a coherence that is anchored in the ontological and epistemological premises of the modern conception of the political. Finally, the article underlines the critical potency that the theoretical legacy of post-structuralism offers to us, facing this landscape.
\end{abstract}

Keywords: post-truth; political ontology; governmentality; post-structuralism 
EN ESTE ARTÍ́CULO BUSCO PROBLEMATIZAR algunas de las premisas que sostienen un cierto diagnóstico sobre la relación entre política y verdad, o política y mentira, en nuestro tiempo. Un diagnóstico que tiende a resonar en el vocablo de la "posverdad" y en una serie de valoraciones y comprensiones epistémicas y políticas que se le asocian, las más de las veces, de manera tácita y no sin cierto automatismo. Para ello, i) en primer lugar, cuestiono la idea de que la indocilidad del discurso frente a ciertas figuras clásicas de la verdad en su circulación en la vida social sea una novedad histórica, como se pretende asumir en este difuso diagnóstico. ii) En segundo lugar, problematizo la idea de que vivamos en sociedades en las que estas figuras clásicas de la "verdad" se hayan retirado de la esfera de la política, argumentando que esto es muy desacertado si atendemos no solo a las dinámicas de la política electoral, sino también al funcionamiento del campo de la técnica gubernamental, campo también decisivo en la agencia y los conflictos políticos de nuestras sociedades. En este campo, las prácticas tecno-gubernamentales que tienden a comprenderse a sí mismas como apolíticas están más bien caracterizadas por una práctica específica, casi que incuestionada en su auto-evidencia, de producción tecnocientífica de verdad sobre lo social, sobre las poblaciones, sobre el crecimiento o el decrecimiento económico, sobre las políticas públicas en todos los campos de la vida social, sus variables, sus medios y sus fines. Los enfoques más generalizados y mediáticos del debate sobre la posverdad deben repensarse a la luz de la hegemonía global de la racionalidad cientifista propia de la ciencia económica en la práctica gubernamental de los Estados contemporáneos, cuyos efectos performativos son notables en la práctica del gobierno estatal desde hace ya varias décadas, tanto en Europa y Estados Unidos (Foucault, 2007b), como en América Latina (Escobar, 1995; Aparicio, Jaramillo \& Manrique, 2017). El interrogante epistemológico y político de nuestra era no es tanto cómo ha llegado a reinar la mentira rampante en el campo de la política electoral, sino más bien cómo han llegado en nuestras sociedades a concurrir, a complementarse, a operar de manera coordinada, aunque seguro con sus tensiones y desfases, la práctica de la hiperverdad en el campo de la tecnociencia gubernamental (técnica eminentemente política a pesar de las pretensiones a contrario de sus agentes), y el desprecio por la verdad en el campo de la realpolitik de la política electoral. ¿Qué estructuras y dispositivos institucionales, epistemológicos y sociales permiten el funcionamiento de dicha concurrencia? Para responder a estas preguntas tomaremos 
la pista de una reflexión de uno de los más emblemáticos representantes de la élite tecnocrática en la historia de Colombia, Miguel Urrutia. iii) Finalmente, y dándole continuidad a la exploración de estas preguntas, sugiero que el "relativismo" voluntarista como modo de comprensión de la política, lejos de derivarse de una presunta condición o mentalidad "posmoderna", como se tiende a sugerir en ciertas discusiones académicas, es un rasgo constitutivo de la concepción distintivamente moderna, liberal y republicana de la política en la figura del contrato social. Esto nos llevará a reivindicar frente a estas críticas las más de las veces generalizadoras, poco rigurosas e imprecisas, la potencia del posestructuralismo como pensamiento histórico, crítico y filosófico frente a algunos de los retos cruciales que enfrentan las aspiraciones democráticas e igualitarias en la contemporaneidad. Reactivar esta potencia exige hoy una reflexión filosófica alternativa sobre el problema de los intercambios entre verdad y política.

\section{El diagnóstico de la "posverdad" y la antiquísima angustia de la filosofía y de la soberanía}

Los usos difusos Del VOcablo POSVERDAD connotan el uso del discurso como arma de combate, de un discurso huérfano y errante que parece haber sido doblemente escindido de la verdad, o al menos de aquellas concepciones de la verdad dominantes en la historia de la filosofía y de la ciencia en Occidente: primero, pues su orfandad consistiría en que no haya una intención o una voluntad sincera y bien intencionada que lo respalde y controle; segundo, en tanto que su errancia consistiría en que su rumbo y sus efectos ya no parecen estar anclados en el fundamento de un mundo objetivo que opere como su referente y su medida (Derrida, 1975, Rancière, 2006) ${ }^{1}$. Discurso sin norma y sin ciencia que hace estragos en la

1 Es bien conocido el lugar central que le otorga Derrida (1975) a la desestima que puede encontrarse hacia ciertas formas de escritura en los Diálogos de Platón y hacia la figura del padre como instancia de autoridad, de fundamento, de soberanía, lo mismo que a la correlativa figura de la orfandad como condición desamparada pero amenazante de dicha instancia: "se sabe cómo insiste Sócrates en la miseria, lastimosa o arrogante, del logos entregado a la escritura [...]. Esta miseria es ambigua: apuro del huérfano, ciertamente, que tiene necesidad no solo de que se le asista con una presencia, sino de que se le asista y se vaya en su ayuda; pero compadeciendo al huérfano, se le acusa también, y a la escritura, de pretender alejar al padre, de emanciparse con complacencia y suficiencia. Desde la posición de quien tiene el cetro, el deseo de la escritura es indicado, designado, 
sociedad cuando cae en manos de los poderosos sin escrúpulos. Algunos analistas caracterizan de este modo, con alarma, al discurso político en la era de la "posverdad", y describen así ese fenómeno masivo de la circulación de información falsa o de valoraciones sin sustento que inciden de manera preocupante en el escenario ambiguo de la "opinión pública", especialmente en la coyuntura de procesos electorales decisivos (brexit, Trump, el No en el plebiscito sobre el acuerdo de paz en Colombia, etc.). Pero frente a esta caracterización de lo que significa el vocablo posverdad como presunto "signo de nuestros tiempos", esa angustia hacia una peligrosidad devastadora del discurso en su circulación proliferante en el campo social, debemos atender a que no hay allí, en realidad, ninguna novedad histórica: esa angustia es consustancial a la historia de la filosofía política en Occidente, y a cierta experiencia y comprensión de lo político en las prácticas sociales condicionada por, y determinante de, esa historia. Esa orfandad y errancia del discurso es lo que Platón lamenta de la "escritura" en el Fedro, y es también lo que lo lleva a condenar los efectos de la mímesis poética en la polis². Es lo que lleva a Hobbes a la necesidad de construir una nueva ciencia de la política, pues la vertiginosa polisemia de conceptos normativos como ley, justicia o soberanía era para él causa indisociable de la guerra civil que desangraba su patria hacia mediados

denunciado como el deseo del huérfano y de la subversión parricida. ¿No es ese fármacon criminal, no es un regalo envenenado?” (pp. 113-114). Asimismo, aludiendo a ese rechazo de la escritura en el Fedro y otros diálogos platónicos, Rancière (2006) ve allí cómo la ley se instituye produciendo una multiplicidad inadmisible que estaría pensada, según su interpretación, como una multiplicidad desbordada que amenaza el orden social dado y sus jerarquías, ya no con la figura de la orfandad, sino del inmigrante, del extranjero, como otro inadmisible: "la ley excluye lo que debe ser excluido, pero lo hace no tanto discriminando propiedades, sino elaborando una categoría específica de lo múltiple como categoría del Otro que no puede ser acogido" (p. 47). En esta clave, entonces, se debería abordar con más cautela la indignación frente a ese discurso supuestamente errante y sin control que causa estragos en la era de la "posverdad", pues esta va las más de las veces aparejada de un juicio moral civilizatorio y pedagogizante hacia la que, desde esa perspectiva, aparece como una multitud anónima, ignorante, amorfa y moralmente deficitaria, que se dejaría afectar o manipular por este discurso perverso.

2 Platón describe en el Fedro esa amenzante orfandad y errancia del lenguaje que tiene lugar en cierto tipo de escritura, en estos términos: "[...] con que una vez algo haya sido puesto por escrito, las palabras ruedan por doquier, igual entre los entendidos que como entre aquellos a los que no les importa en absoluto, sin saber distinguir a quiénes conviene hablar y a quiénes no. Y si son maltratadas o vituperadas injustamente, necesitan siempre la ayuda del padre, ya que ellas solas no son capaces de defenderse ni de ayudarse a sí mismas" (276a). 
del siglo XVII (Hobbes, 2005)³. La portentosa empresa kantiana de salvar de la duda escéptica a los juicios sintéticos a priori de la física newtoniana y cimentar su pretendida objetividad y validez tiene que ver sin duda con el principio de orden que sustenta su doctrina de la unidad de la razón, a pesar de su división entre un uso téorico y un uso práctico: si la razón no puede fundamentar un orden de la naturaleza en su uso teórico, tampoco podrá ser el fundamento de un orden de las costumbres en la vida social.

Este inquietante peligro de un discurso proliferante y sin control es tan antiguo, pues, como la filosofía misma en la historia de Occidente; esa angustia es el Dopplegänger (el doble fantasmagórico) sin el cual la filosofía, la más antigua de nuestras disciplinas académicas, nunca hubiese definido su identidad ni su lugar en la historia de nuestra cultura. No hay pues, nada novedoso en "la era de la posverdad”, definida así en líneas generales; ninguna ruptura epistemológica, ningún nuevo malestar de la cultura, ninguna nueva "era”, ningún apocalíptico fin de los tiempos o doloroso nuevo comienzo.

Quienes sostienen a contrario, sin reparar en el antiquísmo linaje de esta angustia, que con la emergencia de la posverdad ocurrió una fractura sin precedentes en el tejido social, cultural, ético y político de las sociedades contemporáneas, le atribuyen a ciertas corrientes teóricas, que asocian a lo que llaman de manera un tanto imprecisa el posmodernismo, haber contribuído a causar este inédito malestar cultural de nuestros días (Oborne, 2005). Esa extraña postulación de una conexión entre unos filósofos parisinos que pasaron la mayor parte de sus vidas sentados en sus escritorios en algún modesto rincón de sus bibliotecas, frente a una vieja máquina de escribir, y un fenómeno social y cultural de relevancia histórico-mundial, suscita algunas perplejidades. ¿Qué puede ser aquello que

3 Esto es muy claro en el prefacio a El ciudadano, en el que Hobbes (2005) le atribuye a la falta de un conocimiento científico certero sobre los conceptos normativos, la ambición y la avaricia que conducen a la guerra: "y si los filósofos morales hubieran desempeñado su oficio con parecido éxito [al de los geómetras y los físicos], no veo cómo el esfuerzo del hombre habría podido contribuir mejor a su felicidad en esta vida. Pues si se conociera la razón de las acciones humanas con el mismo grado de certeza con el que se conocen las razones de las dimensiones de las figuras, la ambición y la avaricia, cuyo poder se apoya en las falsas opiniones del vulgo acerca de lo justo y lo injusto, quedarían desarmadas" (p. 3). 
media, según este tipo de análisis o diagnóstico, entre un puñado de filosófos y un fenómeno como el de la así llamada posverdad?

\section{La posverdad en la política electoral y la hiperverdad en la técnica gubernamental}

ENTRE LA BIBLIOTECA DEL FILÓSOFo PARISINO y el bullicio de este cuasi apocalíptico caos histórico-mundial, media, según el diagnóstico que acá problematizamos, el "relativismo" como síntoma cultural de nuestra época. Este fenómeno habría sido propiciado en buena parte -así discurre este tipo de argumento- por la puesta en cuestión de la existencia de una realidad objetiva incontestable para cuyo conocimiento las ciencias empíricas (naturales o sociales) habrían desarrollado métodos confiables y verificables. El énfasis que ponen estos análisis sociológicos o histórico-críticos en el devenir histórico de la verdad, y en la misma realidad objetiva de la experiencia social como histórica y culturalmente construída, habría llevado a socavar la confianza en la objetividad de los hechos empíricos, "hard facts", y en la capacidad de la ciencia de regular los debates políticos con la producción de un conocimiento certero y riguroso. Este relativismo como atmósfera cultural sería entonces el caldo de cultivo de políticos corruptos e inescrupolosos que mienten a diestra y siniestra, y manipulan la conciencia de la gente engañándola sin sonrojarse. Este tipo de análisis, podemos darnos cuenta, es extremadamente "objetivista" y "positivista" en lo epistemológico, como es voluntarista e individualista en lo ético-político. Asume que en el campo del conocimiento estamos regidos por un solo referente y nos orienta una racionalidad dura, pero que el campo de lo político es blando, pues la voluntad y la intención de los sujetos flota libre y hace en principio lo que quiere. Se ponen en juego acá una ontología y una epistemología dualistas y metafísicas, que en la concepción de Nietzsche (2008) significan la adhesión a esquemas de comprensión y valoración del mundo y del ser humano constituidos por oposiciones jerárquicas que desdoblan la experiencia de la vida en dos mundos, de los cuales el "superior" irradia una fuerza normativa sobre el "inferior" (p. 23) ${ }^{4}$. Es sobre el

4 "La creencia básica de los metafísicos es la creencia en las oposiciones de los valores. Ni siquiera a los más previsores entre ellos se les ocurrió dudar ya aquí en el umbral, donde más necesario era 
trasfondo de este esquema que se traza la oposición jerarquizada entre el campo del conocimiento, por un lado, y el de la acción ética y política, por otro, y se puede luego sostener que la inmoralidad rampante en este último, el campo de la praxis política, se debe a la inestabilidad o debilitamiento de la capacidad de incidencia del primero, el campo del conocimiento científico del mundo. La indocilidad y violencia de las pasiones se debe a que han dejado de ser gobernadas y disciplinadas por la autoridad de una razón que se abroga el privilegio epistémico exclusivo de la comprensión del mundo tal cual es, y de los hechos tales como realmente son. Se presume que la ciencia, siendo una y estable como el mundo que describe, debería regir sobre la política, múltiple y variable como las diferencias, los puntos de vista y los intereses que allí se ponen en juego. Es este un esquema también viejísimo para responder a la angustia producida por la proliferación de la diferencia y el conflicto en el campo de lo social y de lo político. Un esquema que, con importantes transformaciones, no cabe duda, hemos heredado de Platón, pasando por Hobbes y la tradición entera del contractualismo moderno, y que en últimas es operativo, hoy por hoy, en el modo predominantemente tecnocrático como se gobiernan los Estados neoliberales contemporáneos 5 . Es el esquema de una concepción epistocrática de la relación entre verdad y política; es la idea de que es el conocimiento experto y verdadero del mundo, de un mundo único y en lo fundamental ordenado y estable, accesible a este conocimiento, lo que debe regir y disciplinar el desorden de la política. ¿Es este esquema el que está realmente en crisis hoy, en la así llamada era de la posverdad o, por el contrario, continúa siendo el modus operandi de la gubernamentalidad estatal, en su articulación con la política representativa?

Una de las falencias de esta concepción "voluntarista" de la política como un campo blando, en el que la voluntad estratégica de sujetos con intereses

hacerlo [...]. Pues, en efecto, es lícito poner en duda en primer término que existan en absoluto oposiciones, y en segundo término, que esas populares valoraciones y oposiciones de valores sean algo más que estimaciones superficiales, que perspectivas provisionales” (Nietzsche, 2008, p. 23).

5 Para un desarrollo más exhaustivo de este argumento, según el cual en la comprensión contractualista de lo político, dominante en la filosofía moderna, habría una interdependencia muy fuerte entre una concepción epistocrática y una concepción deliberativa de la relación entre lenguaje, política y sociedad, véase "El discurso de los movimientos sociales como lugar para pensar el conflicto político” (Manrique, 2017). 
específicos termina imponiéndose cuando se cuenta con las mejores armas y se las usa con la mayor eficiencia, es que no atiende a la diferencia de niveles entre la política electoral y la técnica gubernamental, como un rasgo constitutivo del espacio de lo político tal y como tiende de manera predominante a estructurarse en las democracias constitucionales contemporáneas. Por un lado, se juega, en la lógica de la más cruda realpolitik, la disputa por los escenarios de representación política en el Estado; a eso lo llamo el ámbito de la política electoral. Por otro lado, se juega la consolidación de saberes y procedimientos técnicos expertos que tienen la autoridad para decir la verdad sobre cómo gobernar; cómo se diseña una política pública y qué tipo de racionalidad la sustenta para que pueda considerarse idónea; con qué evidencia cuenta, cómo se obtiene, cómo se valida y cómo sirve de base para tomar decisiones sobre educación, salud, empleo, crecimiento económico, etc. Es este el ámbito de lo que, siguiendo a Foucault (2006), llamaríamos la técnica gubernamental. Si bien la "verdad" parece no ser un criterio operativo y eficiente en la movilidad y el funcionamiento del discurso que tiene lugar en la cruda realpolitik, que impera en el ámbito de la política electoral en las democracias liberales modernas, la "verdad" obtenida por el saber técnico especializado no ha dejado de ser el criterio eficiente más decisivo en la técnica gubernamental. La técnica gubernamental que rige las decisiones de política pública y de manejo macroeconómico de los Estados demoliberales modernos, se caracteriza por una agencia (a)política de la hiperverdad: epistocrática, o tecnocrática, de un extremo al otro. Una agencia política que solo actúa, o que pretende solo actuar, a partir de un conocimiento técnico especializado que hoy por hoy produce en su mayor parte la economía como ultra-ciencia social. Se trata de una agencia política tecnocrática que en últimas se concibe a sí misma como apolítica, si asumimos que una de las condiciones de un actuar político es, como lo sugiriera Max Weber (1972), el de una "decisión” sin ninguna garantía cognitiva definitiva. Por el contrario, la tecnocracia como agencia política al nivel de la técnica gubernamental se presume como radicalmente antivoluntarista. El o la tecnócrata no decide, sino que (y la expresión es diciente) "toma una medida". Me atrevería a decir que ni en la Norteamérica de Trump, ni en la Inglaterra del brexit, ni en la Colombia del posacuerdo, se ha desajustado significativamente esta apolitica de la hiperverdad en la esfera de la técnica gubernamental. La pregunta es, entonces, ¿cómo pueden convivir, actuar en conjunto y de manera más o 
menos coordinada, una agencia política voluntarista e indiferente hacia la "verdad" en el ámbito de la política electoral, y la agencia apolítica de la tecnocracia en la que se pone en juego una forma de gobierno de la hiperverdad radicalmente antivoluntarista?

Propongo aproximarnos acá brevemente a esta pregunta a partir de un interesante artículo titulado "On the Absence of Economic Populism", publicado hace ya casi tres décadas por Miguel Urrutia (1991), uno de los representantes más destacados de la tecnocracia antipopulista que ha gobernado en Colombia de manera sostenida, a pesar de los relevos generacionales, desde los años setenta. En este artículo, Urrutia intenta explicar por qué en Colombia, de manera excepcional en el contexto de América Latina, no ha existido lo que él llama "populismo económico" y que define como "intentos de redistribución de la riqueza y del poder a través de un manejo (indebido) de herramientas macroeconómicas" (p. 376), como alzas de salario, control de precios o control monetario. El argumento de Urrutia es detallado y no podemos reconstruirlo aquí. Uno de sus ejes principales, sin embargo, consiste en mostrar cómo el ámbito de la política electoral en Colombia se ha mantenido bajo el dominio del clientelismo y, de esa manera, ha logrado permanecer exento de, e inmune a, las tenazas del "populismo" que, por el contrario, habrían cooptado por momentos los Estados en otros países latinoamericanos -Urrutia cita como ejemplo a la Argentina de Perón, entre otros-. Este eje del argumento es llamativo por el realismo político que lo anima: a pesar de una visión claramente modernizante de lo que es una sociedad bien estructurada, Urrutia no apela a la virtud cívica republicana o a la perspectiva normativa del liberalismo político para evaluar o diagnosticar las dinámicas de la política electoral en Colombia. Reconoce que ellas han estado dominadas por los intereses parciales y particularistas de las élites clientelistas en las regiones y el consecuente intercambio de votos por favores políticos. Aún así, destaca que el clientelismo, imperante en la política electoral, y la tecnocracia al nivel de la técnica gubernamental han podido coordinarse satisfactoriamente a partir de una adecuada distribución del trabajo. El clientelismo media entre el Estado y el votante, concilia intereses y mantiene equilibrios, labor especialmente importante para mantener cierta estabilidad social en las indóciles periferias rurales; pero no interviene al nivel de la técnica gubernamental, es decir, al nivel de la política macroeconómica. La tecnocracia, por su parte, mantiene la estabilidad 
macroeconómica en la aplicación de un saber técnico experto y altamente cualificado; pero, a cambio, se mantiene al margen de las disputas ideológicas sectarias propias de la esfera de la política electoral. En sus propias palabras, Urrutia (1991) afirma:

Una característica del sistema colombiano es que, dado el peligro de concentrar todo el potencial clientelista del Ministerio de Hacienda en las manos de un político [sectario] o de una facción política, se ha dado desde la Guerra la práctica de nombrar a un industrial o a un tecnócrata como ministro de hacienda. Adicionalmente, innovaciones institucionales tales como la creación de la junta del Banco de la Repúplica para manejar la política monetaria, o los contratos con la Federación Cafetera, le han dado al ministro de hacienda un poder casi total en las áreas de política monetaria, fiscal y commercial. Estas íreas han sido pues aisladas de la política del día a día para ser puestas en manos de los tecnócratas. Desde comienzos de los años setentas muchos de los ministros de hacienda han tenido títulos de posgrado en economía, y el resto han trabajado en algún momento como consultores económicos (p. 384; traducción propia) $)^{6}$.

Urrutia no solo acepta en un registro meramente descriptivo esta división del trabajo, sino que la defiende normativamente como un arreglo conveniente que, dadas ciertas condiciones históricas, sociales y culturales, ha mostrado ser beneficioso para el bien común de la sociedad colombiana en su conjunto. El clientelismo concilia intereses y mantiene equilibrios en el campo de la política, campo blando de conflictos y diferencias, y la tecnocracia gobierna en el campo de la economía política, que es el campo duro de la realidad objetiva, de la ciencia y de la verdad. Esta alianza entre tecnocracia y realpolitik, sostiene Urrutia con

6 "One interesting feature of the Colombian system is that, given the danger of concentrating all of the clientelistic potential of the Ministry of Finance in the hands of a politician or a political faction, there has been, since the war, the practice of naming an industrialist or a technocrat as minister of finance. In addition, institutional innovations, such as the creation of the Monetary Board to handle monetary policy, and the contracts with the Coffee Federation, have given the minister of finance virtually total power in the areas of monetary, fiscal, and exchange policy. These areas have therefore been isolated from day-to-day politics and put in the hands of technocrats. Since the early seventies many of the ministers of finance have had postgraduate degrees in economics, and the rest have worked at some time as economic consultants." 
orgullo en este artículo, es lo que ha hecho de Colombia un ejemplo en la región de estabilidad y racionalidad en los indicadores macroeconómicos.

$\mathrm{El}$ argumento está ciertamente muy circunscrito al caso colombiano y, sin embargo, introduce una inquietud interesante que puede problematizar y desplazar las coordenadas en las que se plantea hoy el debate entre política y verdad, o política y mentira: esto es, exclusivamente desde la perspectiva de la agencia voluntarista de líderes específicos en el campo de la política electoral, desatendiendo lo que acontece en el campo de la técnica gubernamental. El auge de la política de la posverdad en el primer campo puede muy bien ir alineado con el auge de la apolítica de la hiperverdad en el segundo.

\section{El relativismo moderno y el tratamiento político de la diferencia}

Pero así COMO LA PARTiCión entre verdad y mentira no es algo que se juega solamente, y quizás no primordialmente, en el campo de la política electoral, sino también en el campo de la técnica gubernamental, habría que decir que el déficit de una contención "normativa" en cualquiera de estos dos campos una contención capaz de modular las prácticas y las conductas de los sujetos a partir de criterios consensuales de justicia, igualdad, respeto, pluralidad, etc.- no proviene de lo que los analistas de la era de la posverdad llaman el relativismo posmoderno. Lejos de ello, ese déficit de contención normativa proviene de un relativismo ético-político en últimas consustancial a la concepción moderna y euro-occidental de la política, y su modo de asentarse en una oposición ontológica tajante y excluyente entre naturaleza y libertad, entre lo objetivo y lo subjetivo. Hay un solo mundo y muchas voluntades; el lugar de la producción de la verdad sobre la realidad objetiva es unívoco, homogéneo, porque la ciencia moderna y su objetivación de lo "real" reclaman una neutralidad e imparcialidad que las distancian presuntamente de la parcialidad política, mientras que esta última, la política, queda arrojada a la diferencia y la heterogeneidad -de intereses, de interpretaciones, de deseos, de cosmovisiones-; una heterogeneidad caótica y conflictiva que es inconmensurable con la "verdad", y cuyo criterio de orientación no puede ser ni epistemológico ni ontológico, sino meramente estratégico. Este relativismo voluntarista que sería una especie de punto cero de la política (el estado de naturaleza en las teorías contractualistas del Estado), y el predominio de 
una racionalidad meramente estratégica allí, no es incompatible con un núcleo normativo que sería el conjunto de ideas reguladoras que dictaminan el deber ser de las instituciones y de los ciudadanos. La realpolitik del interés estratégico, y las normas comunes del deber ser del ciudadano contractualmente legitimadas, se erigen sobre un mismo suelo de asunciones ontológicas y epistemológicas, sobre una misma onto-epistemología social desplegada en esta oposición metafísica entre naturaleza y libertad, entre lo objetivo y lo subjetivo, entre la razón cognitiva y el interés volitivo. Este relativismo normativo, que es una premisa de la concepción totalmente voluntarista de la agencia política en el campo de la política electoral, es un efecto de lo que Bruno Latour (1993) ha llamado la "constitución moderna": la constitución de un mundo en el que "la representación de las cosas a través de la intermediación del laboratorio ha sido para siempre disociada de la representación de los ciudadanos a través del contrato social” (p. 342). Un mundo en el que la objetivación científica de una sola realidad posible se asume como deslindada a nivel ontológico y a nivel epistemológico del conflicto entre voluntades, intereses, deseos. Deslinde del que surgen en todo caso formas coordinadas de constitución de la realidad social en su conjunto. Entre una ciencia presuntamente apolítica, y esta política acientífica, es decir, supuestamente desligada de criterios objetivos de racionalidad y veracidad, para tomar prestada la expresión de Leo Strauss (1998) en su crítica a la oposición metodólogica weberiana entre "hechos" y "juicios de valor", se postulan formas de coordinación que presuponen esa división funcional, y la dicotomía ontológica en la que reposa.

Este relativismo moderno se expresa en un modo muy específico de concebir la cohesión social en la diferencia, y es la idea, como sugiere Latour, del contrato social, una idea que siempre se ha debatido en la historia de la filosofía política moderna, entre la negociación de intereses particulares y la norma común. Al comienzo del Contrato social de Rousseau (2006) esta imbricación recibe una formulación muy precisa: "trataré de mantener en armonía constante, en este estudio, lo que el derecho permite con lo que el interés prescribe, a fin de que la justicia y la utilidad no resulten divorciadas" (p. 5). Como ya lo insinuábamos en el párrafo anterior, esta imbricación nos debe llevar a cuestionar la oposición dicotómica y simplista que tiende a establecerse entre, por un lado, la realpolitik de la negociación de intereses particularistas y la estructura normativa que sirve de ideal regulador en las democracias liberales modernas y que despliega 
el horizonte de las virtudes cívicas republicanas. Esta oposición tan tajante pasa por alto cómo la idea misma del "contrato social" implica siempre complejos enmarañamientos entre esas dos racionalidades: la racionalidad estratégica de la negociación de intereses y la racionalidad normativa del conjunto de valores, principios o normas que serían condición de posibilidad de las leyes comunes.

Así, el antifundacionalismo ontológico en el campo de la política, el modo como este campo queda sustraído del ser y de la verdad -sustraído de una realidad fáctica objetivada que opera como referente del discurso verdadero de la ciencia-, no conduce, como sostienen los analistas de la posverdad, a un simple relativismo normativo del "todo vale" de la realpolitik. Más bien, hay que atender a cómo en la historia del pensamiento moderno ese antifundacionalismo ha estado siempre emparentado con la idea del contrato social como norma de normas. El contrato social como estructura normativa es, pues, relativista, no en el sentido nihilista del "todo vale", que avala las estrategias más inescrupulosas en las que el fin justifica los medios, sino en el sentido justamente de que postula una norma que sirva de criterio para juzgar las prácticas, instituciones y relaciones sociales y que, sin embargo, carece de fundamento ontológico. Es una norma siempre relativa, pues, a la negociación de intereses entre una agregación de individuos. Es una norma sin fundamento otro que el consenso que esta misma negociación de intereses produce, consenso que se estima útil como mecanismo de contención; de contención del conflicto, de la diferencia, de la violencia sectaria, de la dominación, o de ese discurso huérfano y errante que parece tener el potencial de fracturar de manera incesante la estabilidad y la homogeneidad del orden social. Este relativismo normativo que estructura la concepción moderna de la política, y su modo específico de tratar esa diferencia que la atraviesa y la constituye, es pues uno que comparte con la descarnada dinámica de la realpolitik una misma teleología y una misma ontología: el telos del consenso como negociación de intereses; y la ontología de lo social como agregación voluntarista de puntos de vista particulares. Es por esta teleología y esta ontología que les sirven de suelo convergente, que resulta problemático oponer la realpolitik de la disputa descarnada de los intereses, por un lado, y el consenso normativo de las virtudes cívicas, por el otro, como si este último fuese capaz de contener los desmanes de la primera.

$\mathrm{Si}$ el contrato social, como norma por excelencia de lo político en la modernidad, es necesariamente relativista en este sentido epistemológico y ontológico 
-que no coincide exactamente con el juicio moral contra el nihilismo, pero que es su condición de posibilidad-, esto se debe a una concepción intelectualista y subjetivista de la diferencia (sea esta cultural, religiosa, ideológica) por la que pasa el conflicto político. Como si estos conflictos escenificaran creencias, interpretaciones o puntos de vista discordantes de la realidad; o voluntades e intenciones subjetivas de individuos o grupos en un campo de juego por lo demás homogéneo que sería justamente un horizonte de sentido consensual. Suponer que la diferencia y el conflicto políticos pasan por este encuentro y desencuentro de intenciones o creencias subjetivas es acoger la ontología voluntarista de la política en la que se sostiene la idea del contrato social. Quizás uno de los primeros pensadores modernos en poner esta ontología de lo político radicalmente en cuestión fue Marx, al afirmar la idea muy novedosa de que los conceptos, los deseos y los intereses no son subjetivos, sino que se encuentran de cierta manera actualizados, materializados, en la facticidad de la realidad social (Marx y Engels, 1848/2012) $)^{7}$. No son menos reales que el mundo, sino que eso que llamamos "mundo" lo es en la medida en que se sostiene en un suelo semántico, en una estructura de significación, que configura de cierto modo el horizonte de lo posible y lo comprensible. Ese suelo común no es un consenso, como lo presupone el subjetivismo voluntarista intrínseco a la idea del contrato social, y no es tampoco esa realidad objetiva autoevidente en su presunta positividad, propia del cientificismo de la hiperverdad. Es la materialidad de la experiencia histórica en la que estamos situados, que se configura en virtud de que los conceptos, los deseos y las interpretaciones tienen una vida social y no son meramente internos a los sujetos; están más bien dotados de una radical exterioridad que impregna y constituye el mundo que habitamos.

En ese sentido surge para Marx un problema epistemológico de enorme envergadura: ¿cómo puede construirse una ciencia del devenir histórico que esté atenta a esta historicidad de los conceptos, las significaciones, pero que al mismo tiempo

7 Véanse Manrique, 2017 y 2018, para una versión más desarrollada y exhaustiva de esta lectura de Marx como un pensador que comprende la violencia epistémica como constitutiva de la materialidad misma de la experiencia social, históricamente situada, y abre el camino para una teoría crítica de lo social que el posestructuralismo potencia, y cuya vigencia e importancia hoy este artículo busca reivindicar. 
tenga la potencia crítica para problematizar las comprensiones dominantes de lo dado y el conjunto de relaciones sociales en las que estas comprensiones están implicadas (Marx, 1857/1980)? Al hacerse esta pregunta, Marx apela, por supuesto, a una exterioridad inobjetable de lo real: llamémoslo la historicidad, el devenir histórico o la facticidad contingente de lo que acontece. Y le plantea al pensamiento la exigencia de cómo dar cuenta de esa realidad, de cómo comprenderla, de cómo intervenir en ella. Esta exigencia desestabiliza las oposiciones entre lo dado y lo construido, lo natural y lo social, lo externo y lo interno, el objeto y el sujeto, en suma, socava tanto las dicotomías ontológicas en las que está configurada la comprensión moderna de lo político como las dicotomías en las que está sustenta$\mathrm{da}$, asimismo, la ciencia moderna. Pero esta exigencia no conduce a un nihilismo, como aseveran los analistas de la posverdad, sino a una exigencia redoblada de pensar de otros modos la veracidad y la responsabilidad, el conocimiento y la política, y sus relaciones. Es a esta exigencia que responden, en la estela de Marx, esos pensadores posestructuralistas que los denunciantes de la posverdad en nuestra era juzgan con tanta severidad. Hay aún indicios en nuestra contemporaneidad que muestran cuán vigente y relevante es esta tarea, sobre todo cuando se trata de proponer otros ángulos de análisis de los conflictos políticos que pasan por la diferencia cultural o religiosa, por fuera justamente de las figuras dominantes hoy en nuestra episteme de lo político, herencias directas del relativismo voluntarista del contrato social institucionalizadas en los modernos Estados demoliberales: el multiculturalismo o el secularismo. Se trata de analizar cómo estos esquemas normativos para el tratamiento de la diferencia y los conflictos culturales y religiosos, anclados en las premisas ontológicas y epistémicas del relativismo moderno del contrato social, producen también formas de violencia y de desigualdad. Y se trata también de entender cómo el posestructuralismo nos sigue dando herramientas valiosas para este tipo de análisis crítico. Este es, pues, un ejercicio que es acuciante emprender, y que las descalificaciones del supuesto relativismo posmoderno impiden, operando como una cortina de humo.

Para explorar esta potencialidad de la perspectiva crítica posestructuralista, hay que atender a cómo en el mundo contemporáneo la desigualdad 
y la marginalidad tienden a acentuarse no solamente a nivel económico -en la distribución desequilibrada de la riqueza - y no solamente a nivel jurídico-institucional -en el déficit inmenso en la garantía de derechos fundamentales para amplios sectores sociales-, sino también en un nivel distinto, que podríamos llamar onto-epistémico, siguiendo a Marisol de la Cadena (2012). Se trata de una violencia epistémica que deshabilita la capacidad de hacer mundo y de hacer historia de ciertos saberes y formas de comprensión de lo real, asociadas a modos de ser en el mundo. Es la pervivencia incisiva del colonialismo en un mundo poscolonial, en el que las instancias del derecho internacional y el carácter multiculturalista de los Estados demoliberales se han presuntamente erigido como garantías para evitar la imposición de unas culturas sobre otras, que caracterizó la experiencia traumática del colonialismo imperial.

¿Cómo pervive el colonialismo aún en sociedades en las que el derecho nacional e internacional aseguran hasta cierto punto que dicha imposición no se dé por la fuerza de las armas, la represión policial o la ocupación militar? Se trata de esa forma de violencia incisiva que llamamos epistémica, y que puede perfectamente operar y ser efectiva en el marco jurídico-institucional del derecho internacional y del multiculturalismo, porque implica sobre todo la estabilización de unos regímenes de sentido hegemónicos, de unas maneras de comprender el mundo, la sociedad y el ser humano, y de formas de vida asociadas a estas.

No se trata de plantear acá una simple progresión cronológica entre formas de violencia y de ejercicio del poder represivas y productivas, esto es, entre aquellas que silencian saberes y formas de vida, dando la muerte o a partir de la intimidación que la potestad de dar la muerte supone, y otras que favorecen la emergencia de discursos, saberes, formas de desear, prácticas de libertad. Sabemos bien que la distinción entre poder soberano y biopoder en Foucault (2007a), por ejemplo, nunca responde a este esquema simplista de progresión cronológica y que siempre en ese poder represivo, caracterizado por la capacidad de dar la muerte, hay algo también productivo (se incitan conductas, actitudes, relaciones), así como en ese poder biopolítico de "hacer vivir" se conserva una pulsión tanato-política de dar muerte o dejar morir.

Pensadores poscoloniales como Mbembe (2011) han argumentado de manera muy persuasiva, en un diálogo crítico con Foucault, cómo en la experiencia histórica de los países colonizados del sur global el poder de dar muerte se ha 
articulado con el poder que administra la vida, que estructura, que ordena, que organiza, que gobierna, promoviendo e incentivando ciertos usos de la libertad; imbricación que puede responder, en esas historias no europeas, a otras dinámicas que Foucault no supo entrever. En cualquier caso, aún si rechazamos ese tipo de periodizaciones simplistas, la pervivencia del colonialismo en la violencia epistémica actual, que es perfectamente compatible con la estructura jurídica de los Estados de derecho demoliberales, sí señala formas de violencia incisivas que pueden fácilmente pasar desapercibidas e incluso ser tácitamente aceptadas, pues no transgreden los marcos jurídicos y tienden a ser funcionales a las exigencias de desarrollo económico y a la conformación del tipo de individuos y de relaciones que estas suponen. Su invisibilidad y su funcionalidad han hecho de la violencia epistémica, como forma de violencia específica, un eje de análisis central en la teoría crítica de la sociedad contemporánea.

Es preciso decir que, aunque articulada con la explotación económica, la concentración de la riqueza y la represión militar, paramilitar o policial, la violencia epistémica es, no obstante, irreductible a estos fenómenos y requiere ser entonces comprendida y políticamente elaborada en su especificidad. Ello es más relevante aún si entendemos que esta violencia está siempre coimplicada en las otras formas de violencia (económica, armada, jurídica) que reproducen y acentúan la desigualdad social, y que estas últimas no podrían operar sin su concurso. En este sentido, la teoría crítica posestructuralista aporta, justamente, herramientas para poder pensar en escenarios concretos este tipo de violencia específica que acá llamamos epistémica -su funcionamiento incisivo en las condiciones actuales del capitalismo tardío, las formas de colonialismo aún vigentes y sus efectos a la hora de reproducir o incluso acentuar relaciones de desigualdad-; y para poder pensar de manera crítica la exposición de formas de vida vulnerables frente a esta violencia las más de las veces silenciosa, y por ende fácilmente desapercibida.

Este nivel de análisis, no obstante, queda clausurado por dos estilos de "crítica del presente” en la actualidad. Por un lado, queda clausurado por el diagnóstico centrado en la posverdad que venimos problematizando a lo largo de este ensayo, uno que en contra del "relativismo" y de la indisciplina caótica de un discurso que circula huérfano y errante, sin razón y sin referente, causando estragos en el campo de la política electoral, parece reivindicar de manera explícita o implícita una concepción tradicional y metafísica de la verdad, la cientificidad, la razón, la 
relación entre lenguaje y mundo, etc. Concepción que ha sido, y que sigue siendo quizás aún hoy en el modus operandi tendencial de la tecnocracia neoliberal, la principal forma de agenciar la violencia epistémica en la historia de la experiencia colonial y poscolonial, que es la historia del mundo. Este tipo de crítica del presente, muy difundida en los medios de comunicación y la opinión pública, tiene en últimas un efecto conservador del statu quo, pues enarbola el legado progresista de la Ilustración en la identificación de Ciencia - Razón - Igualdad - Libertad. “iEstamos en la era de la posverdad! ¡Se ha retirado la razón de la política! ¡Se ha retirado la ciencia de la política!”. Se avala así la violencia epistémica que la tecnocracia sigue desplegando en nombre de saberes tecnocientíficos y racionalidades hegemónicas, cuya autoridad para gobernar y legislar no ha sido puesta nunca en cuestión; prueba de lo cual es que ni los cuadros burocráticos ni el modus operandi de la tecnocracia economicista se alteran mucho entre un Obama y un Trump, o entre la Inglaterra pre- y la Inglaterra pos-brexit.

Pero el problema epistemológico-político, implicado en el modo como la violencia epistémica continúa hoy reproduciendo otras formas de violencia y de desigualdad en la estructura social, queda clausurado también por otra forma de crítica del presente que está hoy a la "vanguardia" en el ámbito del trabajo teórico y académico. Una forma de crítica que de manera llamativa coincide en algo con el anterior diagnóstico de la posverdad, en tanto que se abroga también el papel de juez en contra del relativismo posmoderno, esta vez enfatizando los peligros de su correlato político, que sería la lucha particularista o identitaria por la diferencia de género, cultural o religiosa (Žižek, 2007; Castro-Gómez, 2015). Este tipo de argumentación desconoce cómo esta política identitaria se ha estructurado en el marco de los Estados de derecho democráticos liberales y su forma peculiar de asumir un modo de tratamiento político de la diferencia (subjetiva, interna, identitaria). Pero esto no tiene nada que ver con el posestructuralismo; todo lo contrario, el problema de la violencia epistémica tal y como se plantea allí nos muestra las deficiencias de esta forma de asumir la diferencia como problema político, y nos ayuda a desinternalizarla, a desubjetivarla y desligarla de la noción de identidad de un individuo o grupo y la ontología social que esta noción presupone. Ontología que, como también he mostrado, se deriva de la comprensión metafísica y dicotómica de lo político que hemos heredado de la modernidad y de la Ilustración. Pero además, este tipo de argumentación corre el 
riesgo de volver a pensar el Estado y la subjetivación política en las coordenadas de sentido ya dadas y estabilizadas por los modos dominantes de comprensión de lo político, a saber, aquellos que se condensan en la herencia moderno-ilustrada del liberalismo político. Sin desplazarlos, sin torsionarlos, acogiéndolos sumisamente e impidiendo que se despliegue entonces esa labor crítica de la teoría que implica objetar y resistir un statu quo semántico y epistémico, dado ya como hegemónico en el orden social. No un sentido común hegemónico relacionado con los temas políticos que se debaten en las escenas de antagonismo y de conflicto coyunturales, pues esta perspectiva entiende bien que un movimiento contrahegemónico implica una disputa por ese sentido común en torno a los temas y problemas intrapolíticos (la salud, la educación, el Estado, el desarrollo). Pero hay otro sentido común ya no intrapolítico, sino metapolítico, que concierne a cómo se concibe lo político en cuanto tal como campo de construcción conflictiva de lo común, y las asunciones epistemológicas y ontológicas que allí se ponen en juego. En este nivel, esta crítica "vanguardista" contra "el relativismo", permanece anclada a lo que Latour (2007) caracteriza como "la constitución moderna”: una onto-epistemología de lo político que hoy por hoy puede ser justamente un obstáculo para entender las dinámicas de la violencia epistémica y su reproducción de la desigualdad en nuestra contemporaneidad, en la medida en que afianza y refuerza una de las principales formas de su agenciamiento, en la dicotomía entre naturaleza y política, entre lo objetivo y lo subjetivo, entre lo empírico y lo normativo.

\section{Referencias}

Aparicio, J. R., Jaramillo, P., \& Manrique, C. (2017). Colombia y la ansiedad universal: Afectos, técnicas y saberes de la modernización. En: A. Tickner \& S. Bitar (Eds.). Nuevos enfoques para el estudio de las relaciones internacionales en Colombia (pp. 167-192). Bogotá: Ediciones Uniandes.

Castro-Gómez, S. (2015). Revoluciones sin sujeto: Slavoj Žižek y su critica al historicismo posmoderno. Ciudad de México: Akal.

De la Cadena, M. (2012). Indigenous Cosmopolitics in the Andes: Conceptual Reflections Beyond Politics. Cultural Anthropology, 25(2), 334-370. 
Derrida, J. (1975). La farmacia de Platón. En: La diseminación (pp. 96-123). (Trad. J. M. Arancibia). Madrid: Editorial Fundamentos.

Escobar, A. (1995). Encountering Development. Princeton: Princeton University Press.

Foucault, M. (2006). Seguridad, territorio y población. Curso en el Collège de France de 1977-1978. (Trad. H. Pons). Buenos Aires: Fondo de Cultura Económica.

Foucault, M. (2007a). Historia de la sexualidad I: La voluntad de saber. (Trad. U. Guiñazu). México: Fondo de Cultura Económica.

Foucault, M. (2007b). El nacimiento de la biopolitica. Curso en el Collège de France de 1977-1978. (Trad. H. Pons). Buenos Aires: Fondo de Cultura Económica.

Hobbes, T. (2005). Del ciudadano y Leviatán. (Trad. E. T. Galván \& M. Sánchez Sarto). Madrid: Tecnos.

Latour, B. (2007). Nunca fuimos modernos, Buenos Aires: Siglo XXI.

Marx, K. (1980). Contribución a la crítica de la economía politica. Ciudad de México: Siglo XXI Editores.

Marx, K., \& Engels, F. (2012). El manifiesto comunista. Madrid: Alianza Editorial.

Manrique, C. A. (2017). El discurso de los movimientos sociales como lugar para pensar el conflicto político. Las Torres de Lucca: International Journal of Political Philosophy, 9, 135-173.

Manrique, C. A. (2018). Derrida leyendo a Marx: lenguaje, historia y promesa. En: L. E. Gama, D. Paredes \& A. Parra Ayala, Diálogos con Marx (pp. 129165). Bogotá: Universidad Nacional de Colombia.

Mbembe, A. (2011). Necropolitica. (Trad. E. Falomir). Madrid: Editorial Melusina. Nietzsche, F. (2008). Más allá del bien y del mal. (Trad. A. S. Pascual). Madrid: Alianza Editorial.

Oborne, P. (2005). The Rise of Political Lying. Sidney: Free Press.

Platón. (1998). El Fedro. En: Diálogos (pp. 393-413). (Trad. C. García Gual et al.). Madrid: Gredos.

Rancière, J. (2006). Lo inadmisible. En: Politica, policía, democracia (pp. 41-58). (Trad. M. E. Tijoux). Santiago de Chile: LOM Ediciones. 
Rousseau, J.-J. (2006). El contrato social o Principios del derecho politico. (Trad. M. J. Villaverde). Madrid: Tecnos.

Strauss, L. (1998). What is Political Philosophy? Chicago: The University of Chicago Press.

Urrutia, M. (1991). On the Absence of Economic Populism in Colombia. En: R. Dornbusch \& S. Edwards (Eds.). The Macroeconomics of Populism in Latin America (pp. 369-391). Chicago: The University of Chicago Press.

Weber, M. (1972). El politico y el cientifico. Madrid: Alianza Editorial.

Žižek, S. (2007). El espinoso sujeto: El centro ausente de la ontología política. Buenos Aires: Paidós. 